\title{
New public management in prehospital emergency services: paramedics' experiences of organizational reforms
}

\author{
Halvor Nordby* \\ Department of health and society, University of Oslo, Norway
}

\begin{abstract}
Background: In recent decades, public health services have undergone major organizational reforms grounded in market ideologies stemming from New Public Management (NPM). Health care workers' perceptions of these reforms have been studied along a number of dimensions, but there has been little focus on how they are perceived in prehospital emergency work.

Research aim: The aim of the study was to understand how paramedics in Norway experience organizational changes related to principles of cost-effectiveness and resource allocation inherent to NPM.

Method: Within a qualitative framework, the study used semi-structured individual interviews and a narrative research method to uncover paramedics' experiences. Giorgio's method of systematic text condensation was used to analyze transcriptions, and the findings were categorized along key thematic dimensions.

Results: None of the paramedics held that structural focus on economy and efficiency had a substantial negative impact on their biomedical work. However, they all agreed that time pressure and resource limitations made it challenging to secure dialogue and provide adequate communicative care. They found it professionally frustrating, but the loser was first and foremost the patient.
\end{abstract}

Discussion: For the paramedics, NPM reforms were not significant obstacles to using technical skills. It was the non-technical dimension of their work that suffered. Time constraints made it impossible to achieve aims of communication and good care.

Conclusion: It has been a widespread view that NPM challenges professional norms of sound practice in care services. The study suggests that this also happens in paramedic practices. The fact that all the informants thought that NPM had significant negative consequences in patient interaction suggests that norms of care are threatened in this area of public health care as well.

\section{Introduction}

Many modern health reforms are grounded in new public management (NPM) - the idea that public service management should be based on principles from the private business sector. NPM has led to more focus on cost effectiveness, resource allocation and a general market orientation in public hospitals and other health institutions. There have been many studies that have aimed to understand consequences of NPM reforms in the area of health care, and how these consequences are shaped by policies, ideologies and new technology [1-4]. Many of the studies have been purely observational in the sense that the aim has been to describe the implementation of NPM reforms. Other studies have added theoretical analyses in attempts to provide deeper explanations of why the reforms have taken place and how they affect public health services [3,5-6].

Ambulance services are an area in which there has been little empirical and theoretical research on the consequences of NPM in health care. The issue of how ambulance personnel experience the recent structural focus on efficiency and resource allocation grounded in NPM has received surprisingly little attention, given the fact that ambulance services are a vital part of the public health sector. Paramedics' professional practices are, to a large extent, grounded in organizational procedures, but there has not been much focus on how modern market ideology affects these procedures and the quality of operative prehospital work.
This article presents a study that sheds light on how paramedics experience organizational changes influenced by NPM ideology. The study sought to understand this by doing in-depth interviews with 30 paramedics from rural and urban ambulance stations. The interviews included issues about experienced consequences of organizational reforms, professional autonomy and ethical dimensions of treatment and care.

The informants were recruited in Norway, but the study has a wider relevance: The phenomenological aim was to gain an exploratory understanding of the perceptions of health care workers who experience the effects of NPM in work with patients. Knowledge of such experiences is, obviously, only one among many elements in an overall understanding of NPM reforms in health services, but there is one important reason for paying attention to how paramedics as front-line workers experience the reforms: paramedics interact directly with patients and have observational knowledge of consequences of organizational reforms in patient interaction.

${ }^{\star}$ Correspondence to: Halvor Nordby, Faculty of medicine, University of Oslo, Department of health and society, PO Box 1089,0315 Blindern, Norway, Tel: 0047 90135154; E-mail: halvor.nordby@medisin.uio.no

Key words: Prehospital health services, new public management, ambulance work, professional autonomy, ethics of emergency care

Received: May 11, 2018; Accepted: May 25, 2018; Published: May 28, 2018 
The next section of the article outlines the background assumptions on which the study was based. The third section presents the study design and the qualitative method that was used in the study. The fourth section presents the main findings, and the fifth and final section discusses these findings.

\section{Background}

Modern health services have undergone reforms that have been analyzed from various theoretical and practical perspectives. Many of these analyses have attempted to dig down under the observable. The aim has not been merely to present empirical data, but also to analyze the mechanisms and ideologies that influence organizational changes [6-8].

In recent decades, New Public Management (NPM) has often been used as a conceptual framework for analyzing core organizational reforms. NPM is an ideology that focuses on how public health services should adapt principles from the private sector. As Peyton (6 p.2) notes, "The main reason is to become more market oriented by holding public institutions accountable for their work performance and increasingly base resource allocation on performance." In health care, the main thrust of NPM lies in its economic-administrative perspective on organizational aims. Performance in health care practices should be measured by objective efficiency goals, and issues of quality should be determined by indicators that focus on transparent, observable and comparable results $[8,9]$.

A fundamental principle in the reforms is that adaption of principles from the private sector will lead to more cost-effective health services and a better correspondence between resource allocation and patients' needs. This is done by defining health personnel as producers of goods that patients are consumers of. Furthermore, an important organizational task is to make sure that the goods are distributed efficiently, by monitoring outcomes and giving incentives such as economic premiering when measurable goals are met. There has been much discussion of the consequences of applying these organizational principles in health care, particularly related to norms of practice in the health professions. Analyses of how the market ideology of NPM constitutes challenges for professional decision-making and the autonomy of health professionals have been developed along a number of dimensions. Some researchers have analyzed the challenges in a descriptive way; their aim has been to understand how NPM principles have been implemented [4-5,10-12]. Others have had a normative ambition, typically by arguing that adaption of NPM principles implies that health care workers' professional integrity and norms of care are undermined [12-15].

The descriptive and normative analyses have different argumentative aims, but as they have been developed, they share a striking characteristic: both types of analysis have been confined to institutional contexts. The purpose has been to understand the implications of NPM reforms inside hospitals, nursing homes and other health institutions.

The institutional area is the largest part of the public health sector, so this is in one sense understandable. At the same time, one must not forget that professional health care work also takes place outside health care facilities. Prehospital practice is one such area. What happens before patients arrive at hospitals in ambulances is an important part of the patient's pathway through the health care system. It is vital that ambulance services function well in themselves, and that they are efficiently linked to adjoining areas of health care. Furthermore, the way patients experience prehospital services influences their general perception of quality and safety [16-18]. This initial encounter means a great deal for how they perceive the care and treatment provided by the health care system.

\section{Study design}

The aim of the present study was to fill in the blanks in our understanding of the implications of NPM in prehospital work. The goal was, more specifically, to understand how paramedics experienced the implications for medical work and care-related communication with patients. The distinction between medical work and communicative health care is not categorical, but it can nevertheless be used as an analytical starting point for exploring these two dimensions of prehospital work.

Furthermore, the significance of making the distinction can be tied to the fact that critical discussions of NPM have often focused on interpersonal relations. A number of theorists have argued that ideals of care are threatened by economic-administrative thinking in health services $[3-7,19,20]$. Meeting norms of care and communication requires time and can easily fall outside what is measured as efficient use of services. An important part of the study was to determine whether this is experienced as the case in prehospital practice.

The study focused on reforms in Norway. The reforms that prehospital services fall under in Norway are part of a national reform of the health services, affecting the specialty of the branches in various ways $[21,22]$. The Norwegian system has properties that cannot be found in other countries, but the key ideas of NPM, as explained above, can be found in many other countries [6-8]. For the purposes of this paper, it is these key ideas that matter. Reforms based on these ideas in other countries will have idiosyncratic properties, but the details do not matter here. The study focuses on the principles of NPM as explained above, and it thus generalizes to other contexts.

\section{Method}

A phenomenological approach was used in the study. The aim was to understand the paramedics' experiences of organizational reforms. A more comprehensive study would have included the experiences of patients and professional co-workers like physicians and nurses, but in order to have a clear determinate focus the study was restricted to paramedics. The intention was to understand how health care workers within the area of prehospital work interpret organizational reforms.

Insofar as the aim was to get knowledge of individual interpretation, the natural choice was to use a qualitative method. The core idea in this method is that an in-depth understanding of informants' thoughts and beliefs can yield important scientific insight. There are various versions depending on the aims and purposes of the research [23-25]. The particular version employed in this study used a reflective lifeworld approach [25]. The idea in this approach is to stimulate reflection while at the same time keeping the focus on how informants experience a phenomenon.

A key concept in a reflective lifeworld approach is narrative. A narrative is the way an event or object is described by an informant, and in narrative research such descriptions are seen as a key source of meaning: utterances do not have isolated significance, they must be interpreted in the light of informants' overall thoughts and beliefs about the topic of discourse $[23,26]$. Thus, a narrative method emphasizes that it is informants' systematic accounts of the world that reveal meaning. The reality, as they understand it, can only be uncovered through principles of coherence and continuous interpretation. 


\section{Informants}

Invitations to participate in the study were published on websites used by paramedics in Norway. The invitations were restricted to personnel who had worked for ten years or more, so that they had experienced organizational changes in recent years. More than 50 paramedics responded, and the respondents were divided into two groups: paramedics from rural areas and paramedics from larger cities. The reason for doing so was that the project sought to uncover whether differences between urban and rural areas affected perceptions of NPM reforms. Apart from this, the project did not make any other formal categorizations like gender or age. The reason why no further inclusion criteria were defined was that the project was designed as an exploratory project with a wide scope. The aim was to get an overall impression of how paramedics experience NPM, not to compare the experiences of various groups of paramedics.

Fifteen paramedics were randomly selected from the rural and urban groups, so that the sample included 30 paramedics in total. These paramedics were sent further practical information about the project and were asked to contact the project leader if they had any questions. Five paramedics had questions of clarification, but none withdrew from the project.

\section{The interviews}

The participants described their experiences in single interviews with a semi-structured design. The idea behind a semi-structured design is to have a plan for the interviews but allow for the plan to modified if the character of the interviews calls for it. In this project, this typically happened when the paramedics talked about an issue that was scheduled to be discussed later in the interview scheme. In such cases it was natural to discuss the issue right away, instead of creating an artificial disruption in the dialogue. All the paramedics shared illuminating stories of how they experienced recent organizational reforms in their services. They provided many accounts of how the reforms had consequences for patient work, and what they thought about these consequences. All in all, the paramedics' accounts yielded comprehensive knowledge of how they experienced their daily work as influenced by a strict focus on resources and cost-effectiveness.

\section{Analysis}

The recordings of the interviews were transcribed and analyzed by using Giorgio's method of systematic text condensation [27,28]. The basic principle in this method is to identify central thematic concepts in interviews, and then gradually refine these concepts on the basis of further analyses. The data material is then codified under thematic concepts, which are used to categorize the main findings of the empirical investigations.

In the present case the initial analysis yielded three main concepts: organizational change, professional autonomy and ethical care. These concepts constituted a framework for systematic interpretation of transcriptions of interviews, in the sense that key expressions used by the informants were categorized under the concepts. For instance, expressions like 'new procedures' and 'economic-administrative management' were assigned to organizational change, and expressions like 'doing good things' and 'trustworthy practitioner' to ethical care. The key expressions were, in turn, linked to the meaning of other expressions the informants used. This way, all the empirical material was systematized within a threefold thematic framework.

\section{Ethics}

Ethical approval from the Norwegian Centre for Research Data (NSD) was sought and received before data collection began. The project was evaluated as acceptable by the NSD, and it was carried out in accordance with the guidelines of the Norwegian National Research Ethics Committees.

\section{Results}

Using the method of systematic text condensation as explained above, the results were categorized under three research questions:

1. How did the paramedics experience the nature of NPM reforms in their own organization?

2. How did the reforms challenge the paramedics' professional autonomy?

3. How did the reforms affect the ethical dimension of treatment and care?

\section{Organizational reforms}

A striking finding of the study was that all the paramedics agreed that there was significant pressure over resources in their daily work. There was, in particular, a great deal of focus on cost-effectiveness. As one of them noted: 'There is so much talk about budgets and economy.' Another said, 'It is so tight. It is all about money.' About two thirds of the informants experienced the economic pressure as massive. Three used the term 'overwhelming.'

Many of the paramedics emphasized that the organizational focus on money was not entirely new. Economy had always been important, but there has been a significant change in the last decade. As one said: 'This issue [economy] gets much more attention now than in the old days.'

It was interesting to note that there was no difference of opinion on this point in the rural and urban groups of informants: all the paramedics held that principles of cost-effectiveness and resource allocation saturated their daily work. The paramedics also agreed that the scope of economic-administrative thinking had a negative impact on their professional autonomy. Many said explicitly that organizational goals were heavily influenced by economic considerations, and that quality measures in patient work were defined by decision-makers who were not very familiar with everyday life in prehospital medical practice. As one of them said, 'In order to define sound quality indicators you must be professional and capable of making autonomous health judgments. The problem is that there is too much economic-administrative thinking centrally.'

Twenty-five of the informants said that one of the main problems was that many decision-makers did not have a relevant medical background and, therefore, limited knowledge of health-based norms of practice. As one of them put it, 'We [paramedics] have a professional culture, shaped by our education and training. The new decision-makers have a different mentality. They think differently.' A fundamental aspect of this problem was perceived to be that leaders in central positions did not interact with patients directly. As one paramedic said, 'Those who make fundamental decisions think in numbers. To them, patients are not individuals they actually see. That does something to it all.' About two thirds of the paramedics thought that this distance between central decision-making and direct patient work had a significant ethical consequence. Traditionally, the aim had 
been to conform to norms of practice as experienced in-patient work, while now, as one said, 'the aim is to not violate the general principles of the law.' This meant that health lawyers had a new role, which one paramedic described as follows:

It used to be more common for there to be conflicts between us and the lawyers. Now we [the paramedics and the lawyers] are united against the economic-administrative thinking in trying to secure treatment that does not violate the minimum criteria of justifiable practice in the law.

The ethical concept of care - understood as good care - was not experienced as part of the economic-administrative pressure. One paramedic said that 'The aim is no longer to do good things in an ethical sense. The much lower threshold is to avoid illegal consequences.' In describing how this change was grounded in modern reforms, six informants actually used the term 'new public management.' As one of them said, 'It is all part of this big new public management reform. It is not the patient first. It is money first.'

\section{Consequences}

The paramedics agreed that principles of cost-effectiveness put pressure on most of their work. One said, 'It is all through the work. We feel it everywhere.' Twenty-five of the informants emphasized that this includes basic medical assessment and procedures. As one of them said, 'We have to act swiftly and make the right choices. Even when there is no urgency in regard to the patient, things must happen quickly.' About two thirds of the informants said that the stress in their daily work was all-encompassing, and all the paramedics held that they felt more stressed than they had ten or twenty years ago.

Even though the paramedics experienced constant systembased pressure, none of them held that it resulted in actions that were unacceptable or that endangered the patients. Moreover, the most important action-guiding rules were formalized in operative manuals as rigid procedures that had to be followed step-by-step. As one paramedic said, 'The procedure system makes sure that the most important somatic issues are addressed properly. Our operative manuals are written by people who know why thorough procedures are necessary. No economic considerations can outweigh this.'

The same point applied to the use of technology like electronic medical equipment and digital emergency networks for communication. All the paramedics described, in various ways, how their use of technology was guided by strict routines that they had learned really well.

At the same time, about one third of the informants complained that they did not have a fundamental knowledge of how the technology really worked. They said that their knowledge was instrumental. As one of them put it, 'When we get new equipment we learn how to use it. That is okay. But we do not really understand how it works.' This made it difficult to get a comprehensive understanding that could help the paramedics when the equipment malfunctioned or had to be used in non-standard ways. Furthermore, in some situations the procedures for using the technology provided insufficient action-guidance. One of them said: 'This practical knowledge of how it works [that we get] is not ideal, but this is the reality now. We learn procedures for standard use.'

There was, however, another dimension of the work in which the consequences of the rigid focus on basic procedures was perceived to be unacceptable in a more fundamental sense. This concerned the interpersonal relations with the patients - how the paramedics were able to interact and talk to them. The most striking finding of the study was that all the paramedics - both in the rural and urban areas - held that they did not have time to do this as well as they should. As one of them said:

Talking to the patient and relatives of patients falls outside the formal procedures. Typically, is into the car as quickly as possible - bang on to the stretcher. Or we leave without the patient as soon as we know that there are no somatic issues. The problem is that we do not manage to explain things we think they are entitled to know. Sometimes they look like big question marks.

The pressure to always 'move on' did not merely limit explanatory dialogue with patients and their relatives. It also influenced the ability of the paramedics to offer care and support. As one of them offered, 'I am not able to come across as a trustworthy practitioner who meets patients with sufficient respect and empathy.' All the informants described this part of their work as the area in which the focus on resources had the most significant negative consequence: the economic-administrative pressure made it impossible to meet ideals of care. When asked to elaborate on how this was the case, three concepts were highlighted:

\section{Information}

The paramedics experienced a mismatch between the amount of information they were able to convey and what they should be able to convey. As one of them noted, 'The patient is entitled to receive much more information than it is possible to give in real life.' Achieving aims of consent and informed patient choices was perceived to be utopian.

\section{Communication}

It was often challenging to make sure that patients grasped messages expressed in words. It took time to uncover patients' ability to understand, and it was difficult to adjust choices of words to that understanding. It was, in particular, difficult to understand how well patients understood explanations, and how the paramedics could use principles of communication to secure dialogue.

\section{Attitudes}

The paramedics did not find it easy to come across as good persons who wanted to take care of the patients. As one of them said, 'How can you give such an impression when there is so little time?' The paramedics wanted to come across as professionals with positive attitudes, but communicating care, compassion and empathy sufficiently well was impossible within the real-life limits of the patient interaction.

It was these limits of dialogue that were perceived as being the main problem with the rigid focus on resources and cost effectiveness. One paramedic put it like this: 'Care and communication are the big losers these days. There is no way we are able to live up to the ideals.' This statement summed up a prevailing view among the informers. It was, in the final instance, the patient's status as an independent decisionmaker and vulnerable, suffering subject that could not be acknowledged in action. It was impossible to act in accordance with ideal professional norms of care.

\section{Alienation}

When the paramedics were asked to explain why they reacted so negatively to the impossibility of giving good care, six of them explicitly used the concept of communicative distance. One even used the concept of alienation to describe how they could not interact with patients: 'We are unable to see the patients as persons. The patients 
become alienated from us because we have to do things so quickly.' This was frustrating: 'It does something to us when we are unable to relate properly.' Another paramedic said, 'It is as if I am working with things instead of other human beings.' Twenty-two of the paramedics, both in the urban and rural areas, held that this did something to their job motivation. One of them said:

When I started here, I wanted to help people. That is why I started in the job. Ofcourse I help them now as well. But far too often, I feel that there is an aspect of the work that I do not like. I do not have time to come across the way I would like to.

Although the paramedics felt that this was a professional defeat for themselves, they thought that it was first and foremost the patient who was the loser. 'The reason why I feel insufficient is that I am unable to live up to the ideals of a caregiver. This is the most important thing.' Many of the paramedics described illuminating situations in which this affected patient. One typical story concerned a weak and elderly patient who needed an explanation regarding why she could not be transported in the ambulance:

We had explained why we could not take her with us, but this was difficult. We tried to explain that we were not doctors and that a doctor would come. But she understood absolutely nothing. She said, 'But aren't you doctors?' I am sure that if we had had more time, we could have explained better. We should have stayed longer, but there was no time.

Another example involved redirection of the ambulance during a transport assignment:

We were going to transport an elderly man to hospital for dialysis. Suddenly there was a cardiac arrest just down the street. We had to leave the transport patient with the home care services, and he had already waited for many hours. This was not easy for the patient. But this is how it is. We do not have enough cars.

The same kind of resource problems arose in transitions at hospitals:

Often when we deliver patients we know that they will have to wait a long time when it is not acute. And often we do not have time to communicate our assessment as well as we would have liked to. Far too often, we have to run on. The patient is left there for a really long time, and we have not been able to convey all the information we want to convey.

Many of the paramedics were eager to share accounts like the one above. As one of them said, 'You have to be there to understand it. Specific cases have to be described to make it clear how it is to be a patient nowadays.' Eight informants said explicitly that describing real life events was the best way of illuminating the consequences of the economic-administrative pressure from central management levels. Giving detailed explanations of their own experiences, and what they perceived to be patients' experiences, was the best way of explaining why they could not interact with patients as they thought they should.

\section{Discussion}

As noted above, the paramedics did not experience the massive focus on economy and resource allocation as a significant obstacle to their medical work. They were, however, concerned about how market ideology and economic thinking threatened ideals of care and led to an objectification of patients. The most striking finding of the study was that the overwhelming focus on cost-effectiveness and resource limitations had a heavy influence on the limits and possibilities of patient dialogue.
The paramedics did not have time to act in accordance with what they regarded as professional norms of care and communication. This view was widely shared by the paramedics - both those who worked in rural services and those who worked in urban areas.

In order to explain this main finding, the concept of non-technical skills is relevant. As Fletcher [29] observes, such skills are "sometimes referred to under the general heading of 'human factors', but more specifically, as they do not relate directly to the use of medical expertise, drugs and equipment (i.e. clinical knowledge and technical skills), they can be described as non-technical skills". Having adequate nontechnical skills is a matter of being able to think analytically, plan the operative work, and secure interaction with other people [30,31].

The concept of non-technicality was originally developed in aviation as a denotation for skills pilots need to have in emergency situations in which procedures constitute insufficient action-guidance. However, in recent years the concept has been recognized as important in acute medicine as well [29]. Furthermore, in this context, an essential non-technical skill is the ability to communicate with patients, and it was especially this dimension of their work the paramedics focused on. They held that the pressure on resources made it impossible to secure good dialogue.

Fundamentally, the paramedics' beliefs about the importance of being able to interact adequately with patients corresponds to the importance of using social interpretive skills. The paramedics regarded social skills as being of crucial importance in the operative work, but lack of time made it impossible to use the skills the way they wanted to. This frustration was the main source of their criticism of economicadministrative thinking.

\section{Social understanding}

A striking consequence of the time pressure in the operative work was that information exchange was challenging. It was difficult for the paramedics to convey all the information they wanted to convey, and it was difficult to understand patients adequately.

For the paramedics, the problem was that they were not able to meet optimal communication conditions, conditions for successful exchange of thoughts, beliefs and other propositional attitudes [33-35]. The paramedics recognized that it was insufficient to state information using mere words. It had to be adjusted to patients' ability to grasp and understand communicative actions. Theoretically this requires, in the first instance, awareness of patients' body language and other observational clues of interpretation. However, observation is only the first step towards understanding patients' beliefs and thoughts [36]. It is also necessary to transcend the outside and access what McDowell [37] describes as the 'inner realm of thought.' It is imperative to be able to grasp an essential part of patients' horizons of understanding - their overall perspective on their state of ill health.

This was precisely what the paramedics felt that they could not do. The pressure to always move on - even in situations that were not acute - meant that they did not have time to uncover patients' horizons. Lack of time made it difficult to understand each patient's individual preferences and need for information. The consequence was that many patients did not get information adjusted to their information needs - information the paramedics thought that the patients were entitled to receive.

\section{Motivation}

For very many of the paramedics, the fact that they were unable to use their non-technical skills was not merely frustrating in itself; 
it also affected their view of themselves as professionals. It affected their motivation and job dedication. In recent years, the significance of job motivation has often been correlated with the concept of work engagement. This concept refers to the process of being intrinsically interested in one's job and individuals' willingness to work towards organizational goals [38]. It is well documented that employees who are motivated and identify with organizational goals tend to work harder than those who do not have these job attitudes [39-43]. For very many of the paramedics, it was this kind of engagement that was threatened by NPM. The pressure from higher ranks was brutal. It was experienced as a one-way monologue about economic-administrative priorities, and there was no real dialogue between their own operative levels and central management levels on which core decisions were made. The paramedics' own beliefs and values about good health care practices were not acknowledged as real-life norms for practice.

\section{The patient as a person}

Even though the paramedics experienced the comprehensive focus on money and resources as personally frustrating, they thought that it was first and foremost the individual patients who were the losers within the new economic-administrative ideology. It was a widespread view among the paramedics that patients were not met as they should be.

Theoretically, this experience of being unable to act in accordance with norms of conduct in patient interaction can be explained in the light of theoretical virtue ethics, a tradition that goes back to the philosopher Aristotle and his analysis of what it means to be a good person [44-48]. Aristotle's philosophy has been interpreted in different ways in health care ethics, but all virtue theorists hold that a virtue such as compassion lies as much in health care workers' attitudes as in their actions [49]. As Davies et al. [50] observe, the idea is that a health care worker who does not have positive attitudes fails to satisfy a fundamental ethical demand, while a health care worker "who responds to a difficult patient care situation with respect, patience and an attitude of care is described as a 'good' person."

It was this ideal of care-based dialogue that underlay the paramedics' frustration of not being able to establish adequate relations to patients. Very many of the paramedics were concerned that the patients did not experience them as persons with positive attitudes who really wanted to take care of them. They experienced a communicative distance they could not overcome. As noted above, one paramedic even used the concept of patient alienation. Even though the paramedics wanted to be perceived as compassionate and caring health care workers, they did not have time to create such an impression. Once again, it was impossible to act in accordance with their own professional norms for practice.

\section{Conclusion}

Securing somatic treatment must be given high priority in organizational designs of prehospital services, but the human factor should not be forgotten. Patients who are transported in an ambulance are suffering human beings who need to be understood and taken care of. There is a limit to how far norms of care can be met by using quality indicators that focus on somatic issues. If the interpersonal dimension of patient work does not get sufficient attention, there is a risk that the work will have unacceptable ethical consequences. This is a general challenge for NPM ideology, and it raises an important question: how should health services reforms meet the total needs of patients, including their need to get information and receive communicative care?

The study presented in this paper has shown that this question is also highly relevant in ambulance services. The study is exploratory, but it nevertheless accentuates a tendency. The fact that all the informants in the study - both in rural and urban areas - felt that they were unable to meet professional norms of care strongly suggests that this is a widespread view among paramedics.

More comprehensive research is needed to gain a more detailed understanding of how various groups of paramedics experience NPM. The study that has been presented here can serve as a starting point for designing further investigations and a framework for explaining why such investigations are important. It is important to remember that the ambulance sector is a large part of the health care sector, and it affects a lot of vulnerable patients who have experienced severe loss of health. How these patients should be met, taken care of and understood as individual subjects is a question that deserves more attention than it receives nowadays.

\section{Declaration of no conflicts of interests}

The author declares that there is no conflict of interests to report.

\section{References}

1. Mattei P (2016) Public accountability and health care governance: Public management reforms. London: Palgrave MacMillan.

2. Anders Ö, Carina AL, Rod S (2016) Management innovations for healthcare organizations: Adopt, abandon or adapt? London: Routledge.

3. Christensen T, Lægreid P (2011) The Ashgate research companion to new public management. London: Routledge.

4. Tulchinsky T, Varavikova E (2014) The new public health. Am J Public Health 94 705-709. [Crossref]

5. Ramesh M, Araral E, Wu X (2010) Reasserting the public in public services: New public management reforms. London: Routledge.

6. Peyton M (2009) New public management in health care: Its effects and implications. Aarhus school of economics.

7. Ferlie E (2017) The new public management and public management studies. Oxford Research encyclopedia of business and management.

8. Gingrich J (2011) Making markets in the welfare state. Cambridge: Cambridge University Press.

9. Cooper Z, Gibbons S, Jones S et al (2011) Does hospital competition save lives? Evidence from the NHS patient choice reforms. The economic journal 121: 554 [Crossef]

10. Simone D (2014) Assessment of new public management in health care: The French case. Health Res Policy Syst 12:1-16. [Crossref]

11. Evans JH, Hwang Y, Nagarajan NJ (2001) Management control and hospital cost reduction: Additional evidence. J accounting and public policy 20: 73-88.

12. Lapsley I (2008) The NPM agenda: Back to the future. Financial accountability and management 24: 77-93.

13. Pollitt C, Bouckaert G (2011) Public management reform: New public management governance and the neo Weberian state. Oxford: Oxford University Press.

14. Maclaugnin K, Osborne SP, Ferlie E (2002) New public management: Current trends and prospects, London: Routledge.

15. Duncan W, Peter M, Ginter L, Swayne J (2013) Strategic management of health care organizations. Oxford: Wiley Blackwell.

16. Blaber A (2008) Foundations for paramedic practice: A theoretical perspective. Maidenhead: Open University Press.

17. Henry M, Stapleton E (2010) EMT prehospital care. St.Lois/London: Mosby.

18. Sanders M (2010) Sanders's paramedic textbook. St. Lois/London: Mosby.

19. Mathis R, Jackson J (2010) Human resource management. Andover: Cengage Learning.

20. Anne Marie Mol (2018) The logic of care. London: Routledge.

21. Lægreid P, Roness PG, Rubecksen K (2006) Performance management in practice: The Norwegian way. Financial accountability and management 22: 251-270. 
22. Pettersen I J (2003) From bookkeeping to strategic tools? A discussion of the reforms in the Nordic hospital sector. Management accounting research 15: 319-335.

23. Berg B, Lune H (2012) Qualitative research methods for the social sciences. Boston: Pearson publishers.

24. Silverman D (2006) Qualitative research: Theory, method and practice. London: Sage publications.

25. Bowling A (2000) Research methods in health. Buckingham: Open University Press.

26. Flick U (2002) An introduction to qualitative research. London: Sage publications.

27. Giorgi A (2009) The descriptive phenomenological method in psychology: A modified Husserlian approach. Pittsburgh, PA: Duquesne University Press.

28. Malterud K (2012) Systematic text condensation: A strategy for qualitative analysis. Scandinavian journal of public health 40: 795-805. [Crossref]

29. Fletcher G, et al (2002) The role of non-technical skills in anaesthesia: A review of current literature. British journal of anaesthesia 88: 418-29. [Crossref]

30. Fletcher G, et al. (2003) Anaesthetists' non-technical skills: Evaluation of a behavioural marker system. British journal of anaesthesia 90 : 580-88.

31. Fletcher GC, McGeorge P, Flin RH, Glavin RJ, Maran NJ (2004) Identifying and training non-technical skills for teams in acute medicine. Quality and safety in health care 13: 80-84.

32. Summers A, Willis S (2013) Human factors within paramedic practice: The forgotten paradigm. Journal of paramedic practice 9: 424-428.

33. Apker J (2011) Communication in health organizations. Boston/Oxford: Polity Press.

34. Littlejohn S, Foss K (2007) Theories of human communication. Belmont, CA: Wadsworth.

35. Silverman J, Kurtz S, Draper J (2004) Skills for communicating with patients. Oxford: Radcliffe Publishers.
36. Street P (2008) Interpersonal communication: A foundation for practice. In A Blaber (ed): Foundations for paramedic practice: A theoretical perspective. Maidenhead: Open university Press.

37. McDowell J (1998) Mind, meaning and knowledge. Cambridge/MA: Harvard University Press.

38. Arnold J, Randall R (2010) Work psychology. Essex: Pearson Education Limited.

39. Bakker A, Leiter M (2010) Work engagement. Hove and New York: Psychology Press.

40. Cameron K, Quinn R (2011) Diagnosing and changing organizational culture. San Fransisco, California: Jossey-Bass.

41. Schein E (2010) Organizational culture and leadership. San Francisco: Jossey-Bass.

42. Truss C, Alfes K, Delbridge R, et al (2014) Employee engagement in theory and practice. London: Routledge.

43. Wentland D (2009) Organizational performance in a nutshell. Charlotte, North Carolina: Information age publishing.

44. Armstrong A (2010): Nursing ethics: A virtue based approach. New York: Palgrave.

45. Benjamin M, Curtis J (2010) Ethics in nursing: cases, principles, and reasoning. Oxford: Oxford University Press.

46. Burnyeat M (1980) Aristotle on learning to be good. In: Essays on Aristotle's ethics (ed A Oksenberg Rorty) Berkeley, LA: University of California Press.

47. Beauchamp T (1991) Philosophical ethics. New York: McGraw-Hill.

48. Foot P (2002) Virtues and vices and other essays in moral philosophy. Oxford: Oxford University Press.

49. Kirk T (2007) Beyond empathy: Clinical intimacy in nursing practice. Nursing philosophy, 4.

50. Davis A, Arosker M, Liaschenko J, Drought T (1997) Ethical dilemmas in nursing practice. Stamford, Conn: Appleton \& Lange.

Copyright: (C2018 Nordby H. This is an open-access article distributed under the terms of the Creative Commons Attribution License, which permits unrestricted use, distribution, and reproduction in any medium, provided the original author and source are credited. 